American Journal of Environmental Sciences 6 (6): 553-559, 2010

ISSN 1553-345X

(C) 2010 Science Publications

\title{
Modelisation of Nitrification under Inhibited Environment by Moving Bed Bio-Film Reactor Technique
}

\author{
${ }^{1}$ Pham Thi Hong Duc, ${ }^{2}$ Le Van Cat and ${ }^{1}$ Jean-Luc Vasel \\ ${ }^{1}$ Liège University, Department of Science and Environmental Management, \\ Longwy Street, $N^{\circ} 185$, B-6700 Arlon, Belgium \\ ${ }^{2}$ Institute of Chemistry, Vietnamese Academy for Science and Technology, \\ Laboratory of Environmental Chemistry, \\ Building A18, $\mathrm{N}^{\circ} 18 \mathrm{~A}$, Hoang Quoc Viet Street, Ha Noi, Viet Nam
}

\begin{abstract}
Problem statement: Nitrification by Moving Bed Biofilm Reactor (MBBR) involves physical, chemical and biological processes to remove toxic ammonia for aquaculture that are governed by a variety of parameters, like substrate and dissolved oxygen concentrations, organic matters, temperature, $\mathrm{pH}$, alkalinity and turbulence level, which impact negatively or positively on nitrification kinetics. Approach: The situation becomes more serious as the reaction rate is inhibited by low ammonium concentration and high salinity. That problems usually occur in treatment systems of aquatic breeding hatcheries. Results: In this study, experiments have been conducted to evaluate the impact of salinity on nitrification rate through kinetic constant $(\mathrm{k})$ and reaction order $(\mathrm{n})$ based on general equation $\mathrm{v}=\mathrm{kC}$. Moving bed biofilm reactor was operated continuously at same initial amounts of nitrogen and Phosphorus very low (oligotrophic conditions). Firstly, over view the impact of salinity on kinetic rate to modeling that effect $\mathrm{k}$ and $\mathrm{n}$ to modelisation that affects and obtained the impact of salinity content in the reaction medium $(\mathrm{X})$ and the acclimatization phase $(\mathrm{Y})$ on the kinetic constant $(\mathrm{k}=0.097 \mathrm{e}(-0.0003 \tilde{\mathrm{Y}} 0.0346) \mathrm{X})$ and on the kinetic order $(\mathrm{n}=(0.0002 \mathrm{Y}-0.0195) \mathrm{X}-0.009 \mathrm{Y}+$ 1.2382). Conclusion/Recommendations: Results from kinetic analysis allowed the prediction of the reaction rate and reaction yield with rather high accuracy, helping the design and operation of a biofilter under practical conditions.
\end{abstract}

Key words: Nitrification under inhibited conditions, Modelisation of Nitrification, Moving Bed Biofilm Reactor (MBBR), biological nitrification, dissolved oxygen concentration, biochemical processes, nitrifying bacteria, oligotrophic conditions, inhibitory factors, wastewater aquaculture, ammonium concentration, kinetic parameters

\section{INTRODUCTION}

The biological nitrification process can occur both in saline water and under oligotrophic conditions, for instance in the case of marine hatchery wastewater treatment or re-circulating aquaculture system. Low ammonium concentration (oligotrophic) and high salinity within a system represent the inhibitory factors of the process, which considerably reduce the nitrification rate. The response of the nitrification at low ammonium concentration, high salinity and the adaptation mechanism of the nitrifying bacteria toward these conditions are still unknown and are under investigation (Moussa, 2004; Malone et al., 2006; Tung et al., 2009).

To design a bio-filter always requires the kinetic parameters under individual operating conditions and involves physical, chemical and biochemical processes. Which are governed by a variety of factors such as substrate, dissolved oxygen concentration, organics, $\mathrm{pH}$, temperature, alkalinity and mass transfer level? Many studies about impacts of these factors upon nitrification kinetics help to predict the performance of a bio-filter for a given application (Chen et al., 2006).

Source of wastewater aquaculture is typically contaminated with low ammonium released from residual foods and excreta of cultivating aquatic animals (rarely exceeded $5 \mathrm{mg} \mathrm{L}^{-1}$ ) and high salinity (10-35 ppt) adapted to the cultural medium. The demanded water quality for recycling must meet the standards applied for individual aquatic species and the nation's regulations commonly lower than $0.2 \mathrm{mg} \mathrm{L}^{-1}$ (WHO, 2006; Zweig et al., 1999). Thus, the purification degree has to be achieved at $96 \%$.

Corresponding author: Pham Thi Hong Duc, Liège University, Department of Sciences and Environmental Management, Longwy Street, N 185, B-6700 Arlon Belgium 
Am. J. Environ. Sci., 6 (6): 553-559, 2010

The biological nitrification process can occur both in saline water and under oligotrophic conditions, for instance, in the case of marine hatchery wastewater treatment or recirculation aquaculture system. Low ammonium concentration (oligotrophic) and high salinity within the system represent the inhibitory factors of the process, which considerably reduce the nitrification rate, (Pant et al., 2005; Chen et al., 2006).

Thus, our research focuses on the kinetic behaviour of nitrification process under low ammonium concentration and high salinity, which are representative of the wastewater characteristics from marine hatchery productions.

Kinetic data of biological nitrification are commonly treated by the Monod model or by first order expression in the case of low substrate concentration (Malone et al, 2006; Watten and Sibrell, 2006). In some circumstances these kinetic models are incapable of analyzing the experiment data and communicating tools, in particular for bio-filter design purposes.

In this study, the kinetic data of nitrification process conducted by Moving Bed Bio-Film Reactor (MBBR) under oligotrophic conditions and in saline medium were analyzed by the general kinetics model of $n$ - the order equation and compared with other data analysis procedures. The established procedure was used to investigate the influence of salinity on the kinetic behaviors of the nitrification process under oligotrophic conditions.

Analysis of kinetical data: The biological oxidation of ammonium is often described by the mixed-order Monod equation:

$$
\mathrm{v}=-\mathrm{d}[\mathrm{C}] / \mathrm{dt}=\left(\mathrm{k}_{\mathrm{m}} \mathrm{XC}\right) /(\mathrm{K}+\mathrm{C})
$$

Where:

$$
\begin{aligned}
\mathrm{d}[\mathrm{C}] / \mathrm{dt}= & \text { The ammonium oxidation rate at the } \\
& \text { concentration } \\
\mathrm{C} ; \mathrm{k}_{\mathrm{m}}= & \text { The maximum rate substrate utilization per } \\
& \text { unit of attached biomass } \\
\mathrm{K} \quad= & \begin{array}{l}
\text { The half saturation constant; } \mathrm{X} \text { the active } \\
\text { biomass concentration }
\end{array}
\end{aligned}
$$

On the other hand, a chemical reaction rate can be expressed in general form:

$$
\mathrm{v}=-\mathrm{d}[\mathrm{C}] / \mathrm{dt}=\mathrm{kC}
$$

where, $\mathrm{k}$ is the rate constant; $\mathrm{n}$ the reaction order.
When the reaction proceeds at low ammonium concentration equation (1) could be converted in firstorder expression with respect to $\mathrm{C}$ which corresponds the Eq. 2 for:

$\mathrm{n}=1 . \mathrm{v}=-\mathrm{d}[\mathrm{C}] / \mathrm{dt}=\mathrm{kC}$

The analytical solutions of Eq. 3 and 2 have following forms:

$\mathrm{C}=\mathrm{C}_{\mathrm{o}} \exp (-\mathrm{kt})$ for $\mathrm{n}=1$

$\mathrm{C}^{1-\mathrm{n}}-\mathrm{C}_{0}{ }^{1-\mathrm{n}}=(\mathrm{n}-1) \mathrm{kt}$ for $\mathrm{n} \neq 1$

To simplify the calculation procedure, linear form $\mathrm{v}=$ $\mathrm{kC}$ or Eq. 4 were used to analyse nitrification kinetic data for the bio-filter design purposes (Watten and Sibrell, 2006).

Hem et al. (1994) treated the nitrification kinetics occurring in MBBR and showed that when the alkalinity was in excess and these was no organic load, either ammonium or oxygen concentration would be limited for the nitrification rate. Furthermore when the oxygen was rate limited, the nitrification rate was then close to a first-order function of oxygen concentration, indicating liquid film diffusion to be an important rate limiting mechanism.

Assuming zero-order kinetics for the conversion in the bio-film lead to a simple mathematical expression for the flux of substrate over the bio-film interface the assumption of zero-order kinetics in bio-film to compute fluxes of substrate into the biofilm and the concentration of substrate in the bulk liquid can produce important deviation from the vigorous solution (Perez et al., 2005).

For a preciser description of kinetic data, Eq. 2 or 5 could be applicated for extracting $\mathrm{k}$ and $\mathrm{n}$ from batch reactor data. There are two ways to calculate $\mathrm{k}$ and (or) $\mathrm{n}$ :

- The kinetic curve of the actual ammonium concentration $\left(\mathrm{C}_{\mathrm{i}}\right)$ at the corresponding time $\left(\mathrm{t}_{\mathrm{i}}\right)$ were used to determine $\mathrm{v}$ by numerical differentiation and thereafter $\mathrm{k}$ and (or) $\mathrm{n}$ from Eq. 2, 3

- The set of values $\left(\mathrm{C}_{\mathrm{i}}, \mathrm{t}_{\mathrm{i}}\right)$ were used to calculate $\mathrm{k}$ and (or) $\mathrm{n}$ directly from Eq. 4, 5 by regression method

\section{MATERIALS AND METHODS}

Attached biomass growth: Polyurethane foam of realy density $33 \mathrm{~g} \mathrm{~L}^{-1}$ in cubic form sized $1 \mathrm{~cm} \mathrm{x} 1 \mathrm{~cm} \times 1 \mathrm{~cm}$ was used as a media for bacteria attachment. For the growing phase, a small quantity of isolated Nitrifiers were seeded into common cultivating medium containing a $10 \%$ volume media under aerobic 
Am. J. Environ. Sci., 6 (6): 553-559, 2010

condition (DO>6 $\mathrm{mg} \mathrm{L}^{-1}$ ). The growing period lengthened for about two months at ambient temperature $\left(30 \pm 2^{\circ} \mathrm{C}\right)$. Before accomplishing individual experiments on the influence of salinity, the attached bacteria were acclimated to the prescribed saline conditions for three weeks.

Reactor and experiment implementation: A plastic container of working volume 6 liters was used as a batch reactor for the nitrification. The media volume occupied $6 \%$ of the total reaction medium and was kept in movement by an aerated air stream with DO content of $6 \mathrm{mg} \mathrm{L}^{-1}$.

The initial ammonium concentration for all experiments was $5 \mathrm{mg} \mathrm{L}^{-1}$ as $\mathrm{N}$. The salinity varied from 0-40 ppt. Measuring ammonium concentration was conducted to a period of $10 \mathrm{~min}$. The total sample volume taken from the reactor for each experiment was less than $3 \%$ of the reaction volume.

The synthetic solution was prepared from tap water with a chemical composition as suggested by Liu and Capdeville (1994) and Yee et al. (2009) in their studies of synthesis water apart from salt content. $\mathrm{pH}$ remained unchanged during the experiment and ranged from 7.4-7.6.

Ammonium, nitrite and other related constituents were analysed according to APHA (Eaton et al., 1995)

\section{RESULTS AND DISCUSSION}

Kinetic data analysis by different procedures: Using the average value couples $\left(\mathrm{C}_{\mathrm{i}}, \mathrm{t}_{\mathrm{i}}\right)$ from the experimental kinetic curve, the reaction rate corresponding to the actual ammonium concentration was determined by numerical differentiation and thereafter for calculating $\mathrm{n}$ and $\mathrm{k}$ from Eq. 2, 3. In another procedure, $\mathrm{n}$ and $\mathrm{k}$ were calculated by regression analysis (trial and error) directly from experimental values $\left(\mathrm{C}_{\mathrm{i}}, \mathrm{t}_{\mathrm{i}}\right)$ (see above). The theoretical kinetic curves were calculated from the corresponding $n$ and $\mathrm{k}$ obtained and compared with the experimental data to get the standard deviation. The kinetic curves calculated by four methods are pictured in Fig. 1 and the standard deviations (in \%) between the calculated and experimental are presented in Table1.

These results pointed out that method IV was the best one for extracting $\mathrm{k}$ and $\mathrm{n}$ from kinetic curves in the batch reactor with a standard deviation inferior to 1\% (Table 1 and Fig. 1).

Procedure test: To verify the confidence of method IV, the correlative values $\mathrm{k}$ and $\mathrm{n}$ were used to predict the kinetic curves for initial ammonium concentrations 3 and $8 \mathrm{mg} \mathrm{L}^{-1}$ at three salinities $(10,20,30 \mathrm{ppt})$ and compare with the experiment data. In all cases the coincidence was achieved very well, the standard deviations ranging 3-10\% (Fig. 4 and 5).
Table 1: Standard deviation of fitting curves by different methods to experiment from nine data sets

\begin{tabular}{|c|c|c|c|c|}
\hline Method & Method I & Method II & Method III & Method IV \\
\hline Standard deviation (\%) & $6-75$ & $10-45$ & $1-35$ & $<1$ \\
\hline
\end{tabular}

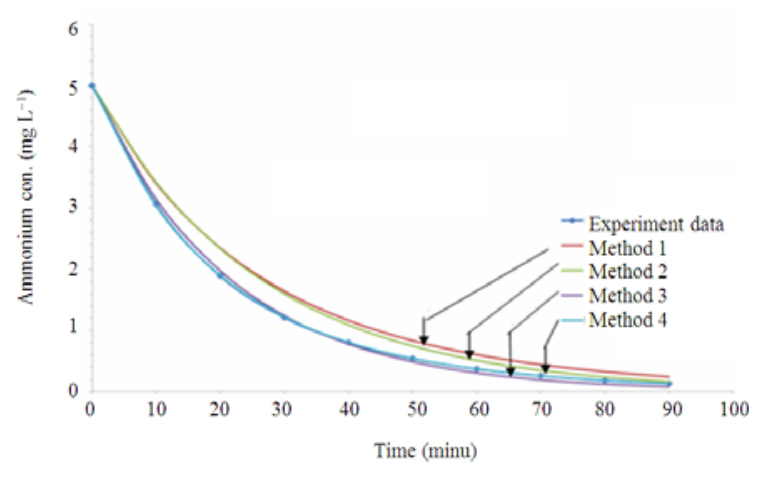

Fig. 1: Comparison of fitting curves calculated by different procedures (see In the text) with the experiment data (the points)

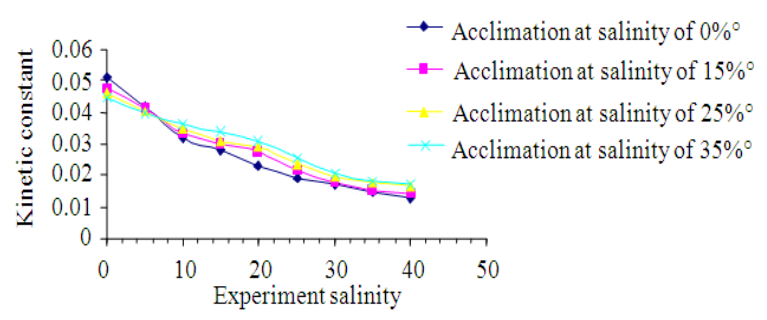

Fig. 2: Kinetical constants $\mathrm{k}\left[\left(\mathrm{mg} \mathrm{L}^{-1}\right)^{1-\mathrm{n}} \mathrm{min}^{-1}\right]$ at different salinity in reaction medium and at acclimation phase

Influences of salinity on the kinetics of nitrification process: The data analysis via method IV was utilized for the further investigation of the influence of salinity on the kinetic of nitrification characterized by the variation of $\mathrm{n}$ and $\mathrm{k}$.

Before performing each experiment set on the kinetic impact by salinity (salinity ranges $0-40 \mathrm{ppt}$ ), the bacteria was acclimatized with the predestined salinity for three weeks. The reaction order (n) and the kinetic constant $(\mathrm{k})$ obtained under variable salinity in the reaction medium and in the acclimation phase and for initial ammonium concentration $5 \mathrm{mg} \mathrm{L}^{-1}$ are tabulated and pictured in Fig. 2, 3, 6 and 7.

The data in Fig. 2 show that the bioactivity decreases by increasing the salinity in the reaction medium for all acclimatization conditions. The major researches gave the same trends with the comments that the declining rate was slowly at the lower salinity and rapidly at the higher salinity content (Dinçer and Kargi, 2001; Liu Ye et al., 2009). 


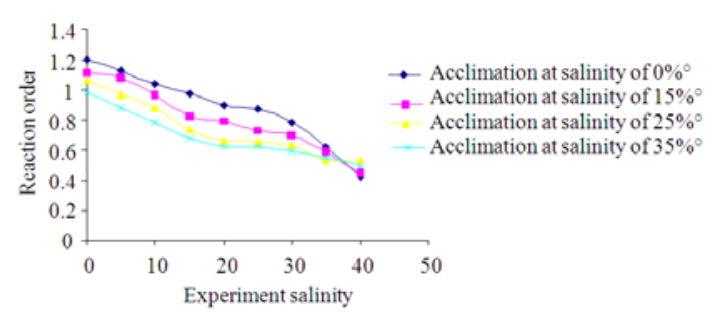

Fig. 3: Nitrification reaction order (n) at different salinity (ppt)

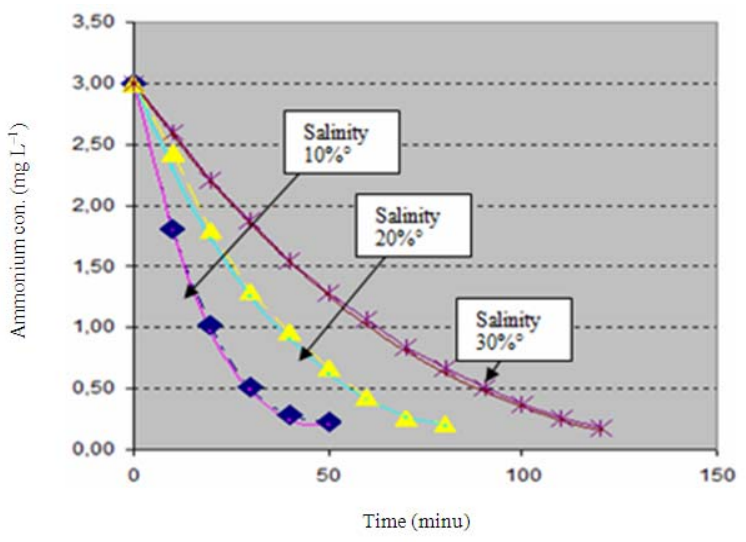

Fig. 4: Comparison between the calculated curves (solid lines) and experiment data (points) for initial ammonium concentration $3 \mathrm{mg} \mathrm{L}^{-1}$

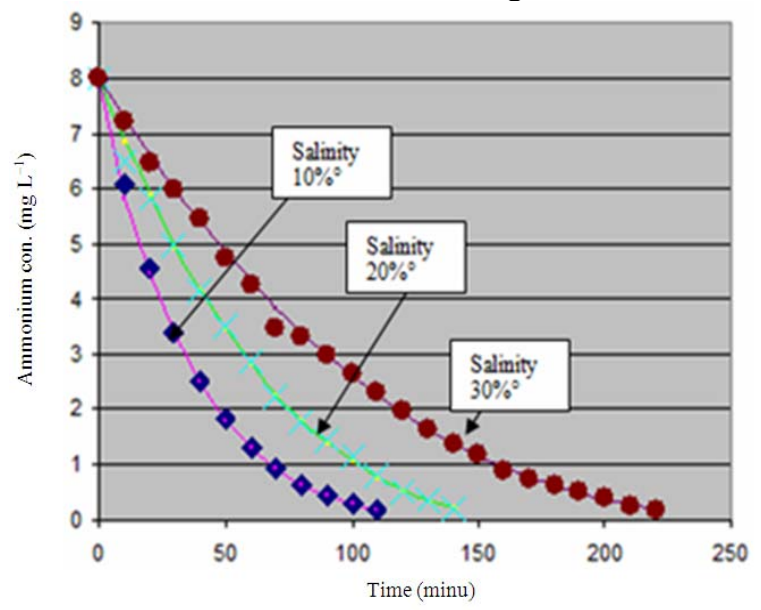

Fig. 5: Comparison between the calculated curves (solid lines) and experiment data (points) for initial ammonium concentration $8 \mathrm{mg} \mathrm{L}^{-1}$

This conclusion was true both in the lower salinity and the in higher salinity acclimatization, especially that declining rate of bioactivity was not rapid as in the case of lower salinity. For microorganisms acclimated in different salinities, the activity responses to the salinity level in the reaction medium were differentiated: in lower salinity of the medium (in same column) the activity was only changed a little and, even in higher level, increased slightly when the acclimation was had done in elevated salinity. In general, the microorganisms acclimated in severe conditions (high salinity) could adapt better to harsh operational situations. This fact means that the adaptation of a fresh water bio-filter to higher salinities was found possible, thus providing an effective tool for a shorter start-up period for treatment of saline wastewater (Chen et al, 2006). The impact of salinity on the kinetical constant will be presented in Fig. 6 .

From the data in Fig. 3 we can see that both at the same salinity acclimation (in arrow) and at the same salinity in the reaction medium (in column), the reaction order decreased with increasing salinity content (Fig. 7).

The order of reaction varied in a wide range, from 1.198-0.4208 when microorganisms were acclimated in fresh water and the nitrification was performed in a reaction environment containing 0-40 ppt of salt. This result was contrary to the traditional expectation which assumed the first-order reaction.

For the acclimation of microorganisms at higher salinities, the variation ranges of $n$ were continually smaller. This could have the following reasons: in a medium of higher salinities the microorganisms were more inhibited by salt, reducing the biological activity (decreasing the reaction constant), leading to lesser demands of ammonium (and other reactants) while the substrate supplies by mass transport remained. The substrate supply was unchanged because of the constant mixing intensity in the reactor (aeration to maintain the moving support media and DO level $>6 \mathrm{mg} \mathrm{L}^{-1}$, mixing intensity impacts of the convective mass transfer), the same size of the support media (influence on the internal diffusion) and the same reaction temperature.

Commonly, the reaction order was assumed to be zero for the high substrate concentration but it was not the case in our study. At low ammonium concentration $\left(5 \mathrm{mg} \mathrm{L}^{-1}\right)$, the reaction order approached to zero when the salinity in the reaction medium increased. Thus, the order of a reaction did not only depend on the substrate concentration, but also on the biological activity of microorganisms, which means on the actual concentration close to the reaction site. The reaction order could be characterized to ratio of the substrate supply due to mass transport and the consume of microorganisms. The abundance of substrate in the reaction region will foster the order of the reaction approaching zero. 
Am. J. Environ. Sci., 6 (6): 553-559, 2010

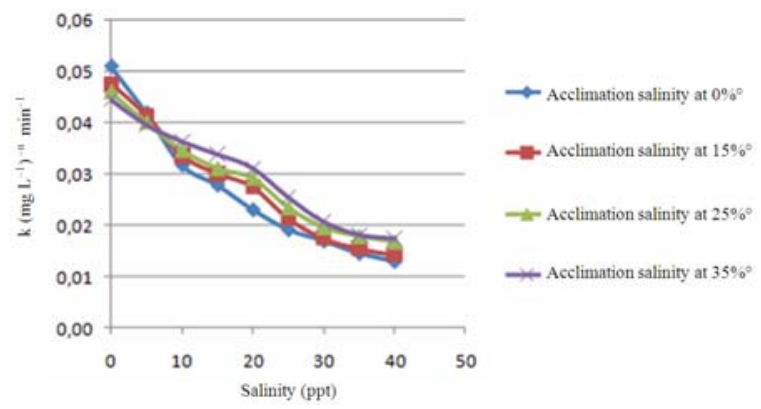

Fig. 6: Kinetical constants $\mathrm{k}\left[\left(\mathrm{mg} \mathrm{L}^{-1}\right)^{1-\mathrm{n}} \mathrm{min}^{-1}\right]$ at different salinity under individual acclimation conditions

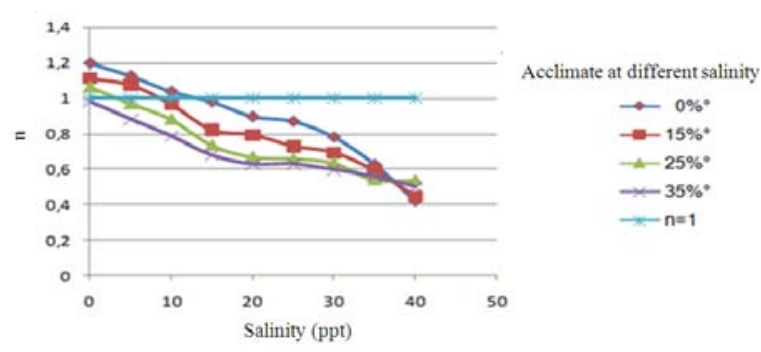

Fig. 7: Reaction order of nitrification at different salinity under Individual acclimation conditions

Table 2: Coefficients ( $a$ and $b$ ) in Eq. 7

\begin{tabular}{llll}
\hline Acclimation at salinity & $\mathrm{a}$ & $\mathrm{b}$ & $\mathrm{R}^{2}$ \\
\hline $0 \%^{\circ}$ & -0.019 & 1.23 & 0.9467 \\
$15 \%^{\circ}$ & -0.017 & 1.12 & 0.9745 \\
$25 \%^{\circ}$ & -0.013 & 1.01 & 0.9304 \\
$35 \%^{\circ}$ & -0.011 & 0.91 & 0.9181 \\
\hline
\end{tabular}

Modeling the impact of salinity on the reaction order: The dependences of the reaction order on the salinity could be modeled via two categories: the salt level in the reaction medium and the acclimatization phase.

From the data received for the influence of salt content on the order of the reaction, the linear mathematical relationship was derived by regression calculation:

$\mathrm{n}=\mathrm{aX}+\mathrm{b}$

The $\mathrm{a}, \mathrm{b}$ are regression coefficients; $\mathrm{X}$ the salt content in reaction medium (ppt).

The values for $\mathrm{a}$ and $\mathrm{b}$ for the different acclimation conditions are represented in Table 2.

It revealed from Table. 2 that $\mathrm{a}$ and $\mathrm{b}$ also varied with the salt level applied in the acclimatization phase, so we could combine this effect to $a$ and $b$ by the formulas:

$\mathrm{a}=0.0002 \mathrm{Y}-0.0195 \mathrm{R}^{2}=0,957$

$$
\mathrm{b}=-0.009 \mathrm{Y}+1.2382 \mathrm{R}^{2}=0.9932
$$

In which, $\mathrm{Y}$ is the salinity content in the acclimatization phase.

So, the impact of both the salt content in the reaction medium $(\mathrm{X})$ and the acclimatization phase $(\mathrm{Y})$ on the order of reaction:

$$
\mathrm{n}=(0.0002 \mathrm{Y}-0.0195) \mathrm{X}-0.009 \mathrm{Y}+1.2382
$$

Modeling the influences of salinity on kinetical constant: For the impacts of salinity on the kinetical constant, we propose the mathematical form:

$\mathrm{k}=\mathrm{c} \mathrm{e}^{\mathrm{dX}}$

$\mathrm{X}$ is the salinity in reaction medium (ppt) $\mathrm{c}, \mathrm{d}$ the regression coefficients.

The coefficients $\mathrm{c}$ and $\mathrm{d}$ were obtained by regression calculation and represented in Table 3.

The values $\mathrm{c}$ in Table 3 remained unchanged $(0.097 \pm 0.001)$, but $d$ varied for different salt levels applied in the acclimatization phase. The influence of salt content in the acclimatization phase on $\mathrm{d}$ could be described:

$\mathrm{d}=0.0003 \mathrm{Y}-0.035 \mathrm{R}^{2}=0.9454$

In general, the impact of the salinity of the reaction medium $(\mathrm{X})$ and the acclimatization phase $(\mathrm{Y})$ on the kinetic constant had the form:

$\mathrm{k}=0.097 \mathrm{e}^{(-0.0003 \mathrm{Y}-0.0346) \mathrm{X}}$

Under the reaction conditions described above, the reaction rate of ammonium conversion was formulated in terms of ammonium concentration $(\mathrm{C})$, the salt content in reaction medium $(\mathrm{X})$ and the acclimatization phase $(\mathrm{Y})$ :

$\mathrm{v}=0.097 \exp ((-0.0003 \mathrm{Y}-0.0346)$

$\mathrm{X}) \mathrm{C}^{(0.0002 \mathrm{Y}-0.0178) \mathrm{X}+1.2469 \exp (-0.0086 \mathrm{Y})}$

Using a, b, c, d parameters according to the conditions: salinity in the reaction medium $30 \mathrm{ppt}$; in the acclimatization phase $20 \mathrm{ppt}$, the calculation of the kinetic curve by applying Eq. 13 was compared with the experiment data. The coincidences between the two procedures were rather well: the standard deviation between kinetically curves and experiment data always less than $10 \%$ (Fig. 8).

The results from the figure show that the mathematical model could be used to predict the kinetic constant, the reaction order and the reaction rate for a given initial ammonium concentration and salinity with a rather high accuracy. 
Am. J. Environ. Sci., 6 (6): 553-559, 2010

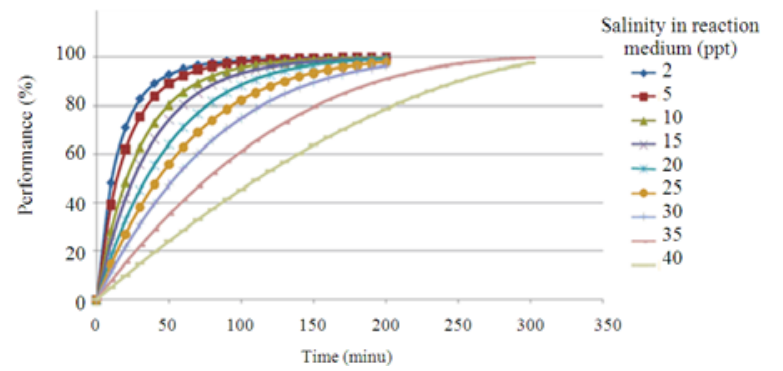

Fig. 8: Comparison of model and experiment data for reaction under Conditions: salinity in reaction medium $30 \mathrm{ppt}$; in acclimation phase $20 \mathrm{ppt}$

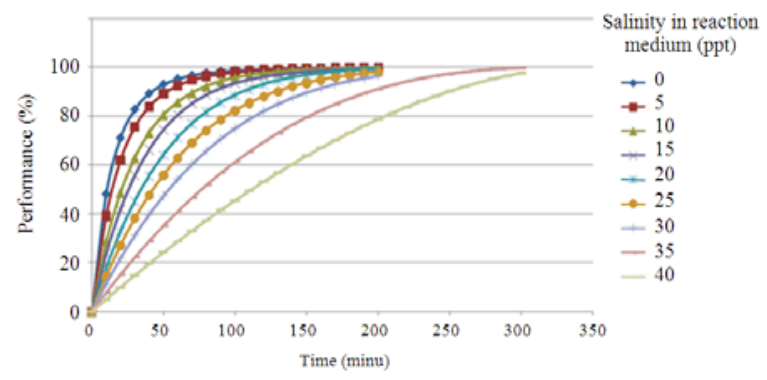

Fig. 9: Reaction performances over time for different salinity in reaction medium

Table 3: Coefficients (c and d) in Eq. 11

\begin{tabular}{llll}
\hline Acclimation at salinity & $\mathrm{c}$ & $\mathrm{d}$ & $\mathrm{R}^{2}$ \\
\hline $0 \%^{\circ}$ & 0.0978 & -0.0343 & 0.9884 \\
$15 \%^{\circ}$ & 0.0977 & -0.0314 & 0.9900 \\
$25 \%^{\circ}$ & 0.0959 & -0.0262 & 0.9882 \\
$35 \%^{\circ}$ & 0.0966 & -0.0251 & 0.9739 \\
\hline
\end{tabular}

Table 4: The time needed (min.) to reach a performance of $96 \%$ with initial concentration of $5 \mathrm{mg} \mathrm{L}^{-1}$ at different salt level in reaction Medium (acclimation at $20 \mathrm{ppt}$ )

\begin{tabular}{lllllllll}
\hline Salt content, ppt & 0 & 10 & 15 & 20 & 25 & 30 & 35 & 40
\end{tabular}

$\begin{array}{lllllllll}\text { Ttime needed (min) } & 34 & 50 & 62 & 76 & 95 & 119 & 149 & 188\end{array}$

Performances of nitrification over time: For the practical applications, the reactor performances over time are of high importance to control the discharged water quality and for economic optimization. The performance of a reaction increases with time and gradually slows down towards the end. The reaction performance is defined as:

$\mathrm{H}=\left(\mathrm{C}_{0-} \mathrm{C}\right) / \mathrm{C}_{0}=\left[\mathrm{C}_{0-}\left(\mathrm{C}_{0}{ }^{1-\mathrm{n}}+(\mathrm{n}-1) \mathrm{kt}\right)^{1 /(1-\mathrm{n})}\right] / \mathrm{C}_{0}$

In this Eq. 15, $\mathrm{H}$ is the performance of the reaction; $\mathrm{C}_{0}$ the initial ammonium concentration; $\mathrm{C}$ the ammonium concentration at time $\mathrm{t} ; \mathrm{k}$ the reaction rate constant, $\mathrm{n}$ the reaction order and $\mathrm{t}$ the reaction time.

The application of Eq. 14 will permit a close watch on the changes of the reaction performances over time in dependence of initial ammonium concentration and salinity (Fig. 9). Following the reaction performances over time was extremely necessary for designing a bio-filter.

The time needed to achieve a given performance is determined from Eq. 15:

$$
\mathrm{t}=\left[\left(\mathrm{C}_{0}-\mathrm{H} \mathrm{C}_{0}\right)^{1 / \mathrm{n}-} \mathrm{C}_{0}{ }^{1-\mathrm{n}}\right] /[\mathrm{k}(\mathrm{n}-1)]
$$

To illustrate the applicability's of Eq. 15, we can take the reuse of wastewater in fish hatchery production as an example. Assuming the ammonium concentration in wastewater will be $5 \mathrm{mg} \mathrm{L}^{-1}$ and the requirement on the treated water $0.2 \mathrm{mg} \mathrm{L}^{-1}$, the removal rate has to achieve $0.96(96 \%)$.

The rate constants of reaction ( $\mathrm{n}, \mathrm{k}$ ) were calculated by Eq. 9 and 12, which are used to determine the times needed to have the reaction performance $96 \%$. Table 4 presents the time reaction needed for the cases of salt level $0,10,15$, $20,25,30,35$ and $40 \mathrm{ppt}$ in the reaction medium, where the microorganisms were acclimated at $20 \mathrm{ppt}$ salt.

The results of Table 4 show the delayed effect of salt content in the reaction medium, for example when the conversion of ammonium is implemented in fresh water, the time needed is only $34 \mathrm{~min}$, but $76 \mathrm{~min}$ for the saline medium of $20 \mathrm{ppt}$.

\section{CONCLUSION}

The nitrification kinetics under oligotrophic condition and salt inhibition procedures in MBBR can be described by a general chemical kinetics formula containing both a reaction constant and a reaction order.

The reaction order varies according to the reaction conditions and could be characterized by the relationship between the substrate consumption and the supplying source or the correlation to the mass transport occurring within the bio-film process.

The impact of salinity in the reaction medium as well as in the acclimating phase affect the kinetically constant and the reaction order could be mathematically modeled. The established model was applied for predicting the kinetic constant, reaction order, reaction rate and performances of the reaction for pre-described conditions and requirements of a bio-filter, which are of importance for designing and operating in wastewater treatment works.

\section{REFERENCES}

Eaton, A.D., L.S. Clesceri and A.E. Greenberg, 1995. Standard Methods for the Examination of Water and Wastewater. 19th Edn., American Public Health Association, USA., pp: 8. 
Chen, S., J. Ling and J.P. Blancheton, 2006. Nitrification kinetics of biofilm as affected by water quality factors. Aquacultural Eng., 34: 179-197. DOI:10.1016/j.aquaeng.2005.09.004

Dinçer, A.R. and F. Kargi, 2001. Salt inhibition kinetics in nitrification of synthetic saline wastewater. Enzyme Microbial Technol., 28: 661-665. DOI: 10.1016/S0141-0229(01)00312-X

Hem, L.J., B. Rusten and H. Odegaard, 1994. Nitrification in a moving bed biofilm reactor. Wat. Res., 28: 1425-1433. DOI: 10.1016/00431354(94)90310-7

Liu, Y. and B. Capdeville, 1994. Kinetic behaviors of nitrifying biofblm growth in wastewater nitrification process. Environ. Sci. Technol., 15: 1001-1013. DOI: 10.1080/09593339409385509

Malone, R.F., J. Bergeronc and C.M. Cristina, 2006. Linear versus Monod representation of ammonia oxidation rates in oligotrophic recirculating aquaculture systems. Aquacult. Eng., 34: 214-223. DOI: 10.1016/j.aquaeng.2005.08.005

Pant, J., H. Demaine and P. Edwards, 2005. Bioresource flow in integrated agriculture-aquaculture systems in a tropical monsoonal climate: A case study in Northeast Thailand. Agricultural Syst., 83: 203-219. DOI: 10.1016/j.agsy.2004.04.001
Perez, J., C. Picioreanu and M. van Loosdrecht, 2005. Modeling biofilm and floc diffusion processes based on analytical solution of reaction-diffusion equations. Water Res., 39: 1311-1323. DOI: 10.1016/j.watres.2004.12.020

Tung, P.G.A., M.K. Yusoff, N.M. Majid, G.K. Joo and G.H. Huang, 2009. Effect of $\mathrm{N}$ and $\mathrm{K}$ fertilizers on nutrient leaching and groundwater quality under mature oil palm in sabah during the monsoon period. Am. J. Applied Sci., 6: 1788-1799. DOI: 10.3844/ajassp.2009.1788.1799

Watten, B.J. and P.L. Sibrell, 2006. Comparative performance of fixed-film biological filters: Application of reactor theory. Aquacult. Eng., 34: 198-213. DOI: 10.1016/j.aquaeng.2005.03.006

WHO, 2006. Wastewater and excreta use in aquaculture. World Health Organization. http://www.thefishsite.com/articles/219/wastewater -and-excreta-use-in-aquaculture

Yee Liu, C. Peng, B. Tang, S. Wang, K. Zhao et al., 2009. Determination effect of influent salinity and inhibition time on partial nitrification in a sequencing batch reactor treating saline sewage. Desalination, 246: 556-566. DOI: 10.1016/j.desal.2009.01.005

Zweig, R.D., J.D. Morton and M.M. Stewart 1999. Source water quality for Aquaculture: A guide for assessment. 1st Edn., The World Bank, Washington, D.C., pp: 62. 